\title{
El terrorismo de estado y el catolicismo en Argentina: el caso de los Misioneros de La Salette*
}

\author{
por Gustavo Morello SJ
}

\begin{abstract}
The aim of this paper is, first, to explore the diversity of Catholic reactions facing state terror in Córdoba, Argentina, during the 1970s. Second, I will analyze how different Catholic groups, because of the state terror, redefined their relations with the church's authority, the state's power and the modernization process. This analysis will be done by focussing on a case study, the so-called "La Salette case", the kidnapping of an American priest and five seminarians in 1976. Starting from the victims' point of view I will try to show how religion played a role during the kidnapping, the reclusion, the torture, and the release process. In this double context - modernization and state terror - this article suggests the existence of four different types of Catholic reactions. One of them supported the totalitarian principles of the government. A second one tried to keep some institutional autonomy, in spite of avoiding defending human lives. A third one tried to preserve lives by using actual institutions. Finally, there was a last one that was looking for a more even relation between the church and the public sphere.
\end{abstract}

\section{Planteamiento}

En los últimos 50 años, la sociedad argentina ha sufrido importantes transformaciones en diversos campos. La más importante ha sido, desde el punto de vista político, la democratización, no sólo en el sentido formal de tener gobiernos elegidos por el voto popular, sino también por la pluralización de la sociedad. La sanción de la ley de "matrimonio igualitario" para personas del mismo sexo es una muestra. Por

* El trabajo es el avance de una investigación para obtener el título de doctor de la UBA en Ciencias Sociales. Además, es parte de un trabajo de investigación de la UCC denominado "Proyectos de olvido y memoria de las víctimas" dirigido por Dr. Carlos Schickendantz. 
supuesto, esta "modernización" social y política impacta también en los actores religiosos. Si bien es cierto que la transformación del campo religioso no ocurre en un momento puntual, creo que en la década de 1970, frente a la violencia del Estado terrorista, cristalizaron las tensiones entre religión y modernidad que de algún modo aún hoy siguen jalonando la relación entre Iglesia Católica, Estado y sociedad.

Ante el terrorismo de estado en Argentina en los años 1970, los referentes sociales católicos reaccionaron de un modo diverso. Los testimonios muestran la presencia de lo religioso en el proceso de oposición, pero también en el de consolidación del terrorismo de estado. ${ }^{1}$ Algunas investigaciones aluden a lo religioso como un insumo ideológico de los aliados al terrorismo, pero también hacen referencia a la convicción religiosa de quienes lo enfrentaron y fueron victimizados por el mismo. ${ }^{2}$ Quienes estudian las posiciones al interior de una institución y hacia fuera, en la trama social, muestran como dichas posiciones condicionan modos de actuar. En esta línea, las proximidades al terrorismo estatal de ciertos sectores eclesiales son explicadas como una alianza estratégica para "ordenar" el interior de la Iglesia; los líderes católicos privilegiaron la unidad eclesial ante cualquier otro valor y usaron el "orden" impuesto por el Estado para sancionar una línea eclesial como hegemónica. ${ }^{3}$ En la misma línea, la oposición al poder ha sido justificada por otra alianza, esta vez con los sectores victimizados. $^{4}$

1 Munú Actis/Cristina Aldino et al., Ese infierno. Conversaciones de cinco mujeres sobrevivientes de la ESMA (Buenos Aires 2001); Familiares de Desaparecidos y detenidos por razones políticas de Córdoba, Por la memoria, por la justicia, por un sueño (Córdoba 2001), Jacobo Timerman, Preso sin nombre, celda sin número (New York 1981).

2 Rubén Dri, Teología y dominación (Buenos Aires 1987); Frank Graziano, Divine Violence. Spectacle, Psychosexuality and Radical Christianity in the Argentine 'Dirty War' (Boulder 1992); Paul Lewis, Guerrillas and Generals. The 'Dirty War' in Argentina (Westport 2002); Patricia Marchak, God's Assassins: State Terrorism in Argentina in the 1970s (Montreal 1999); Emilio Mignone, Iglesia y dictadura (Buenos Aires 1999).

3 Elizabeth Jelin, "The politics of Memory: The Human Rights Movement and the Construction of Democracy in Argentina": Latin American Perspectives 81, 21, 2 (1994), pp. 38-58; Hank Johnston/Jozef Figa, "The Church and Political Opposition: Comparative Perspectives on Mobilization against Authoritarian Regimes": Journal for the Scientific Study of Religion 27, 1 (1988), pp. 32-47.

4 Martín Obregón, Entre la cruz y la espada. La iglesia católica durante los primeros años del 'Proceso' (Buenos Aires 2005); Carlos Torres, The Church, Society, and Hegemony. A critical sociology of religion in Latin America (Connecticut 1992). 
Otras explicaciones, que dialogan con las teorías de la secularización (la pérdida de influencia de las religiones ante el avance de la racionalidad moderna), distinguen un sector mayoritario que, con matices, asumía la marca católica de la identidad nacional y se resistía al proceso de liberalización social y política comenzado con el siglo XX. Otro sector, minoritario, aceptaba la pluralización de la sociedad nacional. El éxito de la estrategia de cada uno de estos sectores se mide por las redes sociales que logró construir y el poder real logrado para conseguir sus objetivos. ${ }^{5} \mathrm{Si}$ aceptamos que una religión tiene en la sociedad el lugar que logra ocupar como oferta válida de sentido, el sector mayoritario explica su fortaleza tanto por la conquista histórica de un espacio relevante de influencia social como porque fue una oferta de sentido aceptada por la sociedad en ese momento. ${ }^{6}$

La religión es una respuesta a la pregunta por el sentido de la vida que refiere a lo sobrenatural y se manifiesta en prácticas, creencias y una estructura social. En el caso del catolicismo, se pretende que ese sentido metafísico sea expresado en realizaciones históricas. Se abre entonces una perspectiva de investigación que indague en las éticas religiosas que guiaron la acción de los católicos en el periodo en discusión.

Entender la relación que se dio entre la vivencia religiosa y la esfera pública desde los sujetos y no sólo de las instituciones supone intentar comprender qué significó el catolicismo para los actores involucrados y cómo ellos se relacionaron con la modernidad. La perspectiva desde el actor permitirá abordar lo religioso: no sólo desde el cumplimiento material de lo prescripto, sino también desde los senti-

5 Roberto Di Stéfano/Loris Zanatta, Historia de la iglesia argentina. Desde la conquista hasta fines del siglo XX (Buenos Aires 2000); Luis Donatello, "La última dictadura militar como problema teológico-político": Fortunato Mallimaci (comp.), Modernidad, religión y memoria (Buenos Aires 2008), pp. 169-180; Mark Osiel, "Constructing Subversion in Argentina's Dirty War": Representations 75 (2001), pp. 119-158; Fortunato Mallimaci, "El catolicismo argentino desde el liberalismo integral a la hegemonía militar": María Cristina Liboreiro et al., 500 años de cristianismo en Argentina (Buenos Aires 1992), p. 197-365.

6 José Casanova, Public Religions in the Modern World (Chicago 1994); Oliveira Lima, D, "Prosperity theology: on the meaning of material success in contemporary urban Brazil": publicado en línea, http://www.irmgard-coninx-stiftung.de/fileadmin/ user_upload/pdf/urbanplanet/collective_identities/Lima_Essay.pdf (último acceso el 5 de marzo de 2011). 
dos dados y los afectos involucrados en la religiosidad del creyente y cómo ésta influyó en su práctica política.

Los objetivos de mi trabajo son, primero, investigar las diferentes reacciones católicas frente al terrorismo de estado en Córdoba en los años 1970; segundo, buscar en esas reacciones los modos de abordar el fenómeno de la secularización y las formas de redefinir la relación de lo católico con lo público. Para explorar la complejidad del comportamiento de los católicos frente a un hecho histórico concreto, emplearé metodologías cualitativas. Ellas servirán para dar cuenta de los sentidos que los actores atribuyeron a sus prácticas, ${ }^{7}$ y lograr generar patrones que, en el marco de la teoría general de la secularización, sean un aporte teórico que dé cuenta de la variedad de catolicismos en la región. Recurriré al "estudio de caso", focalizándome en la persecución a integrantes de la congregación católica Misioneros de La Salette, ocurrida en Córdoba entre agosto y octubre de 1976.

Este caso es relevante por varios motivos. Primero, su accesibilidad: sus protagonistas conservaron la vida y pude entrevistarlos. Fue un hecho que afectó a una comunidad de estudiantes que no estaba vinculada a una praxis política específica. Involucró a víctimas y verdugos católicos, a católicos que ayudaron, motivados por su fe y a otros que por lo mismo negaron ayuda - haciendo posible abordar distintas religiosidades frente al mismo hecho histórico. Los misioneros estaban conectados con otros católicos perseguidos, por lo que formaban parte de una red de víctimas católicas que, por cuestiones de espacio, no se abordarán en este artículo. Finalmente, la repercusión internacional del caso y su impacto en la imagen externa del PRN acentúan su relevancia. ${ }^{8}$ Entiendo que estos criterios hacen del caso una expresión paradigmática del problema social en estudio. ${ }^{9}$

7 Irene Vasilachis (coord.), Estrategias de investigación cualitativa (Buenos Aires 2007).

8 Lucio Garzón Maceda, "Testimonio. La primera derrota de la dictadura en el campo internacional": Hugo Quiroga/César Tcach, Argentina 1976-2006. Entre la sombra de la dictadura y el futuro de la democracia (Rosario 2006), pp. 233-270.

9 Guillermo Neiman/Germán Quaranta, "Los estudios de caso en la investigación sociológica”: Vasilachis, Estrategias de investigación cualitativa (nota 7), pp. 213-237. 
El corpus de este caso está constituido por fuentes secundarias, ${ }^{10}$ documentos del Archivo Provincial de la Memoria (APM) ${ }^{11}$ y del Gobierno de los Estados Unidos, el testimonio de Moore ${ }^{12}$ y entrevistas en profundidad con los involucrados, ${ }^{13}$ debidamente codificadas para proteger su identidad. Estas narraciones biográficas reflejan los conflictos y la trama social del campo católico cordobés de esos años. ${ }^{14}$

\section{El Caso La SAlette: el Catolicismo ANTE El TerRoR}

El martes, 3 de agosto de 1976, a las cinco y media de la tarde fueron secuestrados de su domicilio en el barrio "Los Bulevares" de la ciudad de Córdoba (Argentina) James Weeks, José Luis Destéfani, Daniel García Carranza, Alfredo Velarde, Alejandro Dausá y Humberto Pantoja. En la casa vivía también Don José, un anciano vecino al que cuidaban por su enfermedad, y estaba de visita Joan (Juanita) Mc Carthy, quien trabajaba como misionera en el norte argentino. Los dos últimos no fueron secuestrados.

El barrio de Los Bulevares integraba el cinturón industrial de la ciudad de Córdoba. A pocas cuadras de la casa de los misioneros se encontraba el Centro de Estudios Teológicos a donde concurrían a formarse estudiantes de numerosas congregaciones religiosas de Argentina. Hasta el año 1974 estas congregaciones habían estado estudiando en el Seminario Mayor, perteneciente a la diócesis de Córdoba. Ese año estalló un conflicto entre los profesores del clero y los religiosos, motivado por las diferentes líneas teológicas enseñadas. Los estudiantes protestaron porque los profesores que se iban eran los que los

${ }^{10}$ CONADEP, Nunca más. Informe de la Comisión Nacional sobre la Desaparición de Personas (5a ed., Buenos Aires 1984); CONADEP Delegación Córdoba, Informe (Córdoba 1984); Patricio Rice/Luis Torres (comps.), En medio de la tempestad. Los Hermanitos del Evangelio en Argentina, 1959-1977 (Montevideo 2007); Pedro Siwak, Víctimas y mártires de la década del setenta en la Argentina (Buenos Aires 2000).

11 Archivo Provincial de la Memoria (en adelante APM), Caja "Arzobispado".

12 Carlos Moore, Declaración de Carlos Raimundo (Charly) Moore a los 15 días del mes de noviembre del año 1980 en la ciudad de San Pablo (Córdoba 1980), fs. 42-58.

${ }^{13}$ Entrevistas con Vicente Zueco, Joan Mc Carthy, Rodolfo Emma Rins, James Weeks, Alfredo Velarde, Alejandro Dausá, Jorge Casaretto, Daniel García Carranza.

${ }^{14}$ Fortunato Mallimaci/Verónica Giménez Beliveau, "Historia de vida y métodos biográficos": Vasilachis, Estrategias de investigación cualitativa (nota 7), pp. 175-212. 
alumnos consideraban más capaces (Entrevista, en adelante "e.", 1). A esta medida se agregó otra decisión de las autoridades del Seminario que terminó provocando la salida de los estudiantes religiosos del claustro: la obligación de usar sotana para asistir a clases y de estudiar latín (e. 1, 2, 3).

Las diferentes formas de concebir la formación del clero se debían, en parte, a los modos de ver la crisis de modernidad de esos años. Para un sector, la crisis de secularización era consecuencia de una crisis de valores provocada por el rechazo del mundo a Dios. En este marco, algunos grupos "tenían fobia al comunismo" e interpretaban que la secularización era provocada por "un proyecto de cubanizar la Argentina" (e. 8). En esta concepción, como la crisis de modernidad era producida por la acción intencional de colectivos (como el capitalismo o el marxismo), el lugar de defensa de la fe era el Estado mismo. Desde el poder se debía terminar con la amenaza a los valores occidentales y cristianos.

Para otros, la crisis de increencia era consecuencia de la injusticia. La desatención de la Iglesia a los pobres había provocado que las mayorías se alejasen. Cuando los católicos se dirigieron al trabajo con los marginados (obreros, rurales, etc.), se encontraron con las desigualdades sociales. Y como "parte del mensaje de Cristo es la justicia, entonces no se pueden cerrar los ojos a la injusticia" (e. 2). Esta percepción de la necesidad de dar una respuesta religiosa a la crisis social estaba al origen de la decisión de entrar en la vida religiosa de varios de los misioneros: uno de ellos daba catequesis a los chicos de la calle y es allí donde le "crece un desafío" (e. 4). En tanto que reclamo por la igualdad de derechos ante el Estado y de oportunidades frente a la sociedad, el reclamo de justicia era moderno. Era un impulso religioso que buscaba proteger un derecho para todos, no sólo para los miembros de la corporación. ${ }^{15}$

En todo caso, la solución elegida para el conflicto en el Seminario Mayor fue la separación de los centros de estudios: uno para el clero, el Seminario, y otro instituto para las congregaciones religiosas. Los claretianos ofrecieron un espacio y desde 1975 empezó a funcionar en su casa el Centro de Estudios Filosóficos y Teológicos (Cefyt).

${ }^{15}$ Casanova, Public Religions (nota 6), p. 57. 
EL COMPROMISO RELIGIOSO EN LA CONVULSIÓN SOCIAL

La congregación de los Misioneros de La Salette mudó a sus estudiantes a una casa cercana al nuevo centro de estudios. Los saletenses habían hecho una opción, inspirada en una concepción renovada de la vida religiosa, de vivir en contacto directo con los pobres. El

"[...] compromiso era con el Evangelio [...] y para que [los seminaristas] tengan amor a los pobres estuvimos [...] en villas miserias [...] trabajando [...]. Nuestro carisma es estar con los marginados de la Iglesia y del mundo" (e.1).

Esto implicó vivir austeramente, en barrios obreros, realizando trabajos manuales y buscando alternativas pastorales acordes. Hasta 1975 el seminario funcionó en Yofre, un barrio obrero ubicado al este de la ciudad, con un deficitario sistema de transporte público que dificultaba la asistencia diaria a las clases del Cefyt, por lo que se mudaron al barrio "Los Bulevares". También era un barrio obrero, pero en él estaban más cerca del centro de estudios.

El edificio era el de una vivienda común, autorizada y reconocida por la Iglesia como lugar apto para la formación de futuros sacerdotes. Esta casa sería un problema para los represores, ya que no cumplía con sus expectativas sobre lo que un seminario debía ser. Según Nadeau, el superior de la congregación en Argentina, el general Menéndez le dijo en una entrevista que no entendía como "podía haber un seminario con un solo sacerdote y cinco seminaristas. Que un seminario tenía que ser parecido al ejército - un edificio grande etc." ${ }^{16}$ El obispo auxiliar, Rubiolo, los visitaba habitualmente avalando el estilo de vida elegido.

La distribución de las actividades cotidianas (oración, clases, misa, etc.) era similar a la del seminario tradicional. La diferencia fundamental residía en el trabajo que se hacía tanto al interior de la casa como en el apostolado hacia fuera. Habitualmente, el trabajo de los seminarios tiene dos objetivos: el mantenimiento de la limpieza de la casa y la formación en "humildad" del seminarista. En el caso del seminario saletense, el trabajo era necesario, además, para mantenerse económicamente. "Vivíamos una vida bastante pobre porque era una elección que habíamos tomado" (e. 2). Además del trabajo - de producción avícola y de materiales de construcción -, tenían tiempos de

\footnotetext{
16 APM, Caja “Arzobispado”, Nadeau, Carta a Primatesta del 23 de agosto de 1976.
} 
estudio, de actividad pastoral - en escuelas y barrios - y la celebración cotidiana de la misa. Los impulsaba una "inquietud evangélica" que, en todo caso, puede ser tildada de "romántica o ingenua". La intención era "ir a los límites, vivir el radicalismo evangélico de una vida sencilla" (e. 1, 3, 7). Esto se reflejaba incluso en algunas discusiones domésticas: se recuerdan debates en torno a "si tomábamos o no sopa" (e. 3,4$)$, ya que la gente del barrio sólo consumía un plato de comida. Este tipo de vida los acercó a los vecinos: cuidaban a uno que estaba enfermo, participaban en reuniones por inquietudes barriales, se acercaban a las familias de sus alumnos en el colegio.

La tarea pastoral, por su parte, se desarrollaba en distintos lugares de la ciudad de Córdoba: la zona de Chacras de la Merced, la parroquia de Villa Siburu, y el trabajo con jóvenes de clase media en el Centro de Orientación Vocacional (COV). En febrero de 1976 Weeks asumió la conducción de la parroquia de Villa Siburu. Su párroco anterior, Rodolfo Emma Rins, del clero local, fue atacado a fines de 1975 por una patota que baleó su domicilio. Cuando recurrió a Primatesta, el obispo le dijo que "no podía ser, que él había hablado con gente del Tercer Cuerpo y [Emma Rins] no estaba en ninguna lista" (e. 7). De todos modos, Emma Rins se sintió en peligro y se exilió en Francia. Weeks lo reemplazó en su trabajo.

Otros saletenses trabajaron con jóvenes en el Centro de Orientación Vocacional (COV) vinculado a los Cursillos de Cristiandad, en donde conocieron al padre Vicente Zueco. La vinculación al COV fue sospechada por el Tercer Cuerpo; acusaron a los seminaristas de "reclutar" cuadros guerrilleros en esa organización. Esto es paradójico, ya que los grupos de "Cursillos" eran habitualmente sindicados como de derecha por la vinculación de algunos de sus militantes con las FF.AA.

El trabajo en la zona de las "Chacras", en el este de la ciudad, consistía en la catequesis y la participación como vecinos en los intentos de organizar una cooperativa que ayudase a reconstruir las viviendas dañadas por una inundación reciente. Ahí, también trabajaba gente del Partido Revolucionario de los Trabajadores (PRT), aunque no tuvieron contacto con ellos.

"No trabajábamos en las organizaciones obreras, hacíamos exactamente lo que debe hacer un cura [...] de acuerdo a lo que pedía el Vaticano II, a lo que pedía Medellín y de acuerdo a lo que necesitaba la gente" (e. 2). 
Durante 1975 la represión empezó a operar en la zona de las Chacras, y esto hizo que muchos laicos abandonaran el trabajo en la Cooperativa.

La vecindad con la gente puso a los seminaristas en contacto con la situación de violencia social que reinaba en el ambiente y que los hizo ansiar el golpe de estado como "un alivio" (e. 2). Las autoridades, elegidas democráticamente en Córdoba en marzo de 1973, habían sido derrocadas por el jefe de la policía, Antonio Navarro, en febrero de 1974. A partir de entonces, grupos parapoliciales comenzaron a operar contra todo lo que se consideraba de izquierda. En el invierno de ese año hubo vecinos arrestados y desaparecidos; entre ellos, el hijo de la mujer que cocinaba en la casa de barrio Yofre. Este hecho golpeó la conciencia cristiana de los misioneros que no podían quedarse "sin hacer nada" (e. 2). El ambiente represivo hacía que la gente fuese controlada y detenida en función del estado de sitio. La tensión social era palpable en Córdoba y en otros lugares del país. Al regresar de un retiro, el domingo, 5 de octubre de 1975, los seminaristas fueron detenidos cuando ingresaban a la ciudad. Fue el día en que Montoneros intentó tomar el Regimiento 29 de Formosa. A partir de ese momento se sintieron vigilados por civiles armados que cada tanto los abordaban para cuestionar sus ropas, barbas, peinados, etc.

A pesar del golpe, la tensión social no cedió. Las noticias de las desapariciones aumentaron. Los saletenses entendieron que, desde su "convicción cristiana, no podían desentenderse de lo que sucedía" (e. 2). Sus familiares, y otros colegas de la congregación, les plantearon la conveniencia de mudarse de Los Bulevares por el riesgo que implicaba. Los superiores pidieron a los seminaristas que tomaran una decisión. La determinación de asumir las consecuencias prácticas de sus creencias los impulsó a "acompañar a los vecinos". Esta interpretación del catolicismo había sido fomentada y formada por el "estilo de vida responsabilizador" implementado en el seminario. Así, en un proceso que llevó algún tiempo, decidieron que en función de esta educación y de la sinceridad con la que asumieron el compromiso evangélico, debían solidarizarse con la suerte de sus vecinos. Nadeau y Weeks los avalaron. Cualquier otra salida era "un privilegio social que ignoraba lo que el Evangelio nos pedía". Esta forma de vivir y comprender la vida religiosa en el contexto concreto sería considerada peligrosa, el "gran pecado" (e. 2) del que los acusaran en el Tercer Cuerpo. 


\section{LAS RELIGIOSIDADES EN EL SECUESTRO}

La tarde del 3 de agosto llegó una patota del D2, el servicio de inteligencia policial, y permaneció en la casa hasta entrada la noche, esperando que todos los miembros de la comunidad llegaran al lugar. Los últimos en llegar esa noche se demoraron un poco más porque "andábamos tratando de buscar el diario" (e. 3). En esos días se hablaba de un traslado eventual de Martínez de Perón desde su prisión en el Messidor, en Neuquén.

Según Moore, ${ }^{17}$ el grupo secuestrador estuvo integrado por unos diez policías, todos de "buena apariencia, buena ropa, pelo en orden, bien afeitados", todos entre "35 y 50 años aunque dos eran más jóvenes". ${ }^{18}$ Durante el secuestro la patota simuló pertenecer a los Montoneros "haciendo justicia revolucionaria" (e. 5). Los golpearon, ataron y amenazaron de muerte; rompieron toda la casa buscando armas y, finalmente, la saquearon. Se fueron dejando pintadas que incriminaban a los Montoneros en el hecho.

Toda la situación les hizo pensar que "venían a matar[los]" pero la inesperada presencia de Juanita y José desbarató los planes. Juanita apareció como una "salvadora" (e. 2, 3, 6). La patota "revienta la casa", se burlaron de un cuadro de Carlos Mugica ${ }^{19}$ escribiendo "kaput" sobre el mismo (e. 5) y profanaron la capilla pintando una cruz esvástica y disfrazándose con las ropas utilizadas para la misa. Sin embargo, el violento raid fue detenido por esta mujer sola que, ante el baile sacrílego, llamó al jefe y le pidió que los detuviera. "La capilla quedó en desorden, el tabernáculo abierto, pero las hostias en su lugar, aparentemente sin tocar". ${ }^{20}$

El hecho de la profanación de los ornamentos, considerados sagrados, no se explica cabalmente desde el conservadurismo católico. Si a este tipo de catolicismo se le puede atribuir el menosprecio de las personas concretas, es en función de las reglas rituales. ${ }^{21}$ No es probable

${ }^{17}$ Moore, Declaración (nota 12), p. 52.

18 APM, Mc Carthy, declaración.

19 Mugica fue uno de los miembros del Movimiento de Sacerdotes para el Tercer Mundo, un colectivo sacerdotal comprometido socialmente con los pobres, que llegó a congregar al $10 \%$ del clero argentino. Mugica, quien vivía en una "villa miseria" y militaba en el peronismo, fue asesinado el 11 de mayo de 1974 en la ciudad de Buenos Aires.

20 APM, Mc Carthy, declaración.

${ }^{21}$ Casanova, Public Religions (nota 6), p. 16. 
que una persona creyente, tributaria del catolicismo conservador, profane elementos sagrados. Es más bien una mentalidad fascista, areligiosa, la que guiaría una acción de este tipo. Según la declaración de Moore, ${ }^{22}$ el operativo contra Weeks fue "una acción netamente fascista". En el barrio donde trabajaba había una Unidad Básica controlada por la Alianza Libertadora Nacionalista, la extrema derecha del Partido Justicialista, que recelaba del ascendiente social que iban logrando los religiosos en el barrio, desplazando a los grupos tradicionales. Emma Rins afirma que ellos fueron los autores de la amenaza que sufrió. La policía los "reprimió con cierta independencia" (e. 3) del Tercer Cuerpo, y no hubo confusión: el objetivo eran ellos. "El problema era que trabajaban con los pobres y los pobres se unen" (e. 3). La misma acusación recibirían los jesuitas Jalics y Yorio, detenidos en mayo en Buenos Aires, mientras fueron torturados en la ESMA. Al igual que los saletenses, serían liberados en octubre de 1976, días antes de la reunión de la Asamblea Permanente del Episcopado. ${ }^{23}$

Juanita presenta, en cambio, un tipo de religiosidad preocupado por lo ritual, pero que se ocupa de cuidar la vida. Su pronta denuncia fue lo que en definitiva salvó a los misioneros. La dejaron, posiblemente porque la tomaron por desequilibrada, recomendándole que se presentase en las oficinas de los diarios locales, comunicando el "procedimiento de justicia montonera" (e. 5). Mc Carthy, en cambio, se dirigió primero a la casa claretiana y luego al arzobispado. Durante la madrugada la única puerta abierta que encontró en el edificio episcopal fue la del Servicio Sacerdotal de Urgencia. Allí consiguió un teléfono y habló con Zueco. Zueco se entrevistó con ella y comenzó sus gestiones. Llamaron al consulado norteamericano, porque la familia de Weeks era "electora de los Kennedy" (e. 1, 6). El cónsul viajó a Córdoba el día siguiente y "empezó a tomar un poco carácter internacional la cosa" (e. 6).

Juanita desayunó con el obispo auxiliar, Monseñor Rubiolo, en la mañana del 4 de agosto. Ese día, el mismo en el que asesinarían a

22 Moore, Declaración (nota 12), p. 51.

${ }^{23}$ El 25 de octubre de 1976 comenzó la 34 Asamblea Permanente del episcopado argentino, que el 30 de octubre emitió dos comunicados: uno sobre la oración y el otro un documento aclaratorio sobre la "Biblia Latinoamericana", una edición de la Sagrada Escritura que, aprobada por diversos episcopados latinoamericanos, había sido cuestionada fuertemente por los obispos argentinos más conservadores. 
Angelelli en La Rioja, Primatesta "estaba en Roma" (e. 1). Por eso el obispo auxiliar acompañó las primeras gestiones oficiales. Mc Carthy dejó por escrito "todo lo que podía recordar" (e .5) y huyó de Córdoba. Luego de pasar por Buenos Aires, Uruguay, Paraguay, Bolivia y Ecuador, llegó a Estados Unidos, donde empiezaría a realizar gestiones vinculadas al caso. Por su parte, Zueco intentó averiguar algo a través de un abogado amigo suyo, secretario de gobierno de Córdoba, quien le respondió en principio que no "sabía nada", ya que no habían "intervenido" en el caso. De todos modos, investigó y "sí, los tenían en el Cabildo", en donde funcionaba el D2. Zueco intentó verlos inmediatamente, pero amenazaron con dispararle si se acercaba. A través de un militar amigo logró hablar con un jefe de la Fuerza Aérea local. Este hombre logró "blanquearlos" y le dijo que "no los van a matar", que la situación "está controlada" (e. 6).

En el D2, además de golpizas y otras vejaciones, les tomaron fotos, les pintaron los dedos y les hicieron firmar documentos. Allí funcionaba el "Comando Libertadores de América", que había comenzado a operar en la intervención federal del brigadier Lacabanne y que luego, manteniendo cierta autonomía, funcionó coordinado por el Tercer Cuerpo. Según Moore, ${ }^{24}$ el interrogatorio de Weeks lo dirigió el comisario Tissera, quien les decía que Weeks "era de la CIA".

En el caso de los seminaristas, quien los interrogó fue un "sumariante policial" qué se presentó con el nombre de Î́talo Bocina. "Me sacó las vendas de los ojos" porque quería que lo reconocieran y dijo que "si algún día me encuentran por la calle, sepan que fui una buena persona. No sé, no sé qué preguntarles" (e. 2). El caso de Bocina es significativo, ya que lo describen como una persona "decente, buena, humana" que a pesar de estar desbordada por la situación, trataba de mejorar la vida de los detenidos. Su caso remite a un grupo de personas que, siendo miembros de las fuerzas de seguridad, aparecen más como "víctimas de las circunstancias" que como proactivos en la represión; personas que "fueron en cierto modo víctimas", a pesar de ser policías. Según los entrevistados, eran "pobres tipos" (e. 2) que no tenían forma de salirse, gente que estaba en una situación difícil.

Luego de tres días en el cabildo los llevaron a la penitenciaría. Allí compartirían unas horas en el pabellón de los presos políticos con políticos y sindicalistas, para quienes la prisión era un avatar propio

${ }^{24}$ Moore, Declaración (nota 12), p. 52. 
de la práctica política argentina de aquellos años, por lo que eran más experimentados en la vida de la cárcel. A pesar del aislamiento estaban informados y, como sabían que los llegados eran religiosos, les informaron sobre el asesinato de Angelelli y los ayudaron a estar juntos porque "creían que" también los "iban a matar" (e. 4) - un miedo fundado en acontecimientos recientes: los secuestros y asesinatos de referentes religiosos en distintos puntos del país. ${ }^{25}$

\section{LO RELIGIOSO Y LA TORTURA}

Después de esas horas en la penitenciaría, los alojaron en la Cárcel de Encausados. La vida en Encausados se caracterizó por la dureza en sus condiciones: aislamiento, falta de aseo, comida y ropa. "En esa celda [...] era un lago de bosta y orina [...] yo vivía arriba de la mesita, que era el único lugar seco" (e. 2). Había un grupo de guardiacárceles sádicos, "enfermos", que "disfrutaban haciendo sufrir" (e. 2). Uno de los guardias le dijo a uno de los presos que no tenía escrúpulos por matar, porque "yo mato en nombre de Dios" (e. 1). También hubo miembros del Servicio Penitenciario de Córdoba, cercanos a uno de los seminaristas, que se encargaron de avisar a su familia de la situación en la que estaba; estos guardias "usaban los espacios que tenían para alivianar" (e. 2) la situación de los presos.

Para ser interrogados eran llevados al centro clandestino de detención "La Perla", en las afueras de Córdoba. Paradójicamente, estos momentos violentos eran los únicos de interacción permitidos, en el régimen de total aislamiento en el que estaban. La tortura fue llevada a cabo por un grupo especializado en el mundo católico cordobés, integrado por gente que tenía conocimientos de filosofía y teología. Este hecho contrasta con la situación del D2, donde el interrogador que los recibió no sabía qué preguntarles. Los torturadores conocían

${ }^{25}$ Un mes antes (el 4 de julio) habían sido asesinados cinco religiosos palotinos en Buenos Aires, y 15 días atrás habían matado en La Rioja a los padres Longeville y Murias, a quienes José Luis Destéfani había visitado en abril. En esa semana de agosto, además del secuestro propio y del asesinato de Angelelli, hubo un allanamiento a la parroquia de Goya, Corrientes, en la que trabajaba el padre Ramondetti, unos de los referentes del MSTM, quien pudo exiliarse. El 17 de agosto serían detenidos el obispo de Santa Fe, Vicente Zaspe, y el dirigente Adolfo Pérez Esquivel en una reunión convocada por el Leónidas Proaño, obispo en Riobamba, Ecuador. 
minuciosamente las actividades de varios referentes religiosos locales. Un suboficial, que se identificó como Rubén Magaldi, ${ }^{26}$ "manejaba un grado notable de información sobre la Iglesia cordobesa" (e. 2, 3, 4). Tal vez por eso y por sus manías místicas lo apodaban "el Cura" (e. 3). Otro militar, quien posiblemente haya hecho cursillos con Zueco, se hacía llamar "Juan XXIII" y, en medio de los tormentos, les decía "yo voy a rezar por ustedes, recen ustedes por mín" (e. 3). En La Perla les preguntaron sobre los libros secuestrados, la vestimenta, la barba, etc. Todo era probatorio de la actividad subversiva. Los libros que "más preocuparon" eran los del filósofo Enrique Dussell (mendocino exiliado en México en 1975 por las amenazas y atentados recibidos desde 1973) y los de "paraliturgias", término que los militares asociaban con "paramilitar" (e. 2, 4). Los oficiales de inteligencia también secuestraron documentos eclesiales "no siempre libres de sospecha". ${ }^{27}$

Mientras que uno de los seminaristas talló una cruz y un rosario "para buscar ayuda en la oración" (e. 3), otros recuerdan que los traslados hacia y desde La Perla fueron momentos de ruego intenso a Dios. Siempre pensaron que en uno de esos momentos los matarían. Weeks, el único sacerdote del grupo, celebraba rudimentarias misas:

"[...] en la cárcel [...] hablamos por la ventana [...] cada día, a las 5, digamos, vamos a celebrar misa, nos daban [...] un pan grande todos los días, y [...] Tengo agua y pan, vamos a hacer el milagro [...] sabíamos que cualquier día [...] habían matado a Murias y [...] todo eso [...] iban a matarnos" (e.1).

Dada la incomunicación, esa misa a viva voz era una actividad riesgosa.

En las entrevistas que realicé se mencionó la presencia de Dios varias veces. "Yo pienso que [...] está trabajando en la historia y a pesar de nosotros" (e. 1). Dios aparece de forma real, imposible de negar, salvando en varias oportunidades. "Dios fue cercano todo el tiempo" (e. 2, 5). Cotidianamente, los protegió librándolos de los castigos que suponía violar la disciplina carcelaria. A través de la experiencia dolorosa, consideran que Dios "salvó a otros de sufrir lo mismo"; después de lo que pasó con ellos se "paró todo" (e. 2, 3, 4). El caso La Salette se transformó, según la percepción de algunos

${ }^{26}$ Según la orden de procesamiento del Poder Judicial de la Nación (7 de octubre de 2009), se trata de Roberto Nicandro Mañay, personal civil de inteligencia del Ejército, que operaba - conforme se desprende de su legajo personal - con el seudónimo de Rubén Norberto Magaldi.

27 APM, Menéndez, Informe. 
entrevistados, en un punto de quiebre: el terrorismo de estado no pudo seguir operando sobre el campo católico como lo había hecho hasta entonces.

La presencia en el ámbito del Tercer Cuerpo de este grupo de torturadores especializados hace pensar en cuadros preparados para atacar directamente a la Iglesia, institución que las autoridades consideraran "infiltrada" por el comunismo. Los soldados se consideraban salvaguardas del catolicismo auténtico que luchaban por un país mejor. Un cierto límite a la tortura, impuesto por "el temor a [que] la condición de religiosos" de los torturados implique una "sanción canónica", hace pensar en cierta religiosidad más cercana al conservadurismo, a diferencia del fascismo notado en la patota.

Estos torturadores respondían a una decisión política de las autoridades represivas que "estaban trabajando para herir a la Iglesia" (e. 2). La represión a católicos no responde a casos aislados, sino a la persecución de una red que era entendida como una quinta-columna comunista "infiltrada en la Iglesia desde Medellín". Los acusaron formalmente de "seguir a Medellín". ${ }^{28}$ En esta mentalidad, la vida religiosa que llevaban en Los Bulevares aparece como una "prueba" de su "marxismo" (e. 2). Los militares que los detuvieron consideraban que Primatesta era "sensible a ideologías apátridas" y que monseñor Bordagaray, el encargado de la Acción Católica local, era "ideológicamente ambiguo" (e. 3). Convencido de su función purificadora de la Iglesia y el catolicismo continental, Menéndez fue el artífice de esta persecución; un objetivo más propio del Ejército que de la policía. La Iglesia de Córdoba, dirigida por el "Cerdo Rojo", apodo dado por Menéndez a Primatesta, estaba en la mira del general.

De todos modos, Primatesta aparece como una figura ambigua. Defiende a los misioneros presos en el intercambio epistolar con el Tercer Cuerpo y ayuda con las entrevistas de las autoridades de la congregación y los militares; actitudes que posiblemente contribuyeron al desprecio que tenía Menéndez por el obispo. Pero esto no basta para que las víctimas reconozcan la gestión del arzobispado. Una de las razones de esta resistencia está en la convicción que en el arzobispado "sabían lo que pasaba" en el D2 y "no hicieron nada" (e. 2, 4), tal vez por un apego absurdo a las normas rituales que lo terminaron aislando de la realidad social. Algunas de las víctimas consideran que ésta era una religiosidad

\footnotetext{
${ }^{28}$ Ibidem.
} 
inauténtica: "tienen rituales, tienen un montón de cosas, pero no creen" (e. 7). Frente al terrorismo estatal y la convulsión social se refugian en ritualismos vacíos. Para otros, Primatesta estaba "sobre todo muy asustado y pensaba que los milicos [militares] eran capaces de hacer cualquier cosa y que no había forma de frenarlos". Por eso optó por no despertar al león (e. 6), es decir, no provocar la ira de Menéndez.

El obispo auxiliar, monseñor Rubiolo, respaldó a los detenidos. Él los identificó como seminaristas ante el Tercer Cuerpo de Ejército: el 6 de agosto le escribe una nota al "general de brigada Juan Bautista Sasiaiñ, 2do J y JEM Área 311", en su carácter de "obispo auxiliar y vicario general a cargo del gobierno de la Arquidiócesis", afirmando que los cinco seminaristas "son estudiantes de la congregación" ${ }^{29} \mathrm{En}$ cambio, "la Iglesia" los consideró unos "dementitos" (e. 2), no los reconoció como católicos perseguidos, "no ayudó [...] no me acompañó" (e. 4); ni se reconoció a si misma perseguida, dado que "las líneas [internas estaban] muy enfrentadas [...] entonces no se veía un ataque a la Iglesia como tal porque eran de un sector contra otro, porque los militares eran todos católicos [...]" (e. 8).

Tortolo, el vicario castrense y obispo de Paraná, negó un pedido expreso del provincial de la congregación para lograr la asistencia sacramental de los reos: no gestionó que les permitieran recibir ni los sacramentos ni la Sagrada Escritura. Estamos frente a una religiosidad diferente: un fundamentalismo nacional católico que les negó los auxilios espirituales, tal vez porque los reos eran considerados "subversivos apátridas" (e. 4), alejados de la misericordia de Dios porque con su vida cuestionaron el dogma nacional-católico. Si los sacramentos y la Biblia son para los verdaderos católicos, la exclusión de los detenidos de la lectura de la Sagrada Escritura o su inmerecimiento para recibir la eucaristía y la confesión simboliza que los misioneros presos no fueron considerados auténticos creyentes y son, por lo tanto, apartados de la comunidad. Esto produjo "mucho dolor" (e. 2), "un dolor sumamente grande, que la Iglesia me dé la espalda" (e. 4): los seminaristas, animados por las declaraciones episcopales de Medellín y los superiores de la congregación, se "comprometieron" (e. 2) con un proceso de renovación institucional, para luego ser abandonados y desconocidos por la misma institución que los alentó a realizar las acciones por las que fueron secuestrados.

\footnotetext{
${ }^{29}$ APM, Rubiolo, Carta.
} 


\section{LA LIBERACIÓN Y LOS ACTORES RELIGIOSOS}

Weeks, por ser ciudadano norteamericano, fue liberado y expulsado del país a los quince días. La disyuntiva que se le planteó, ya fuera de Argentina, era entre la presión pública o las gestiones privadas. Todas tenían sus riesgos y sus ventajas. Una vez en Estados Unidos optó por denunciar lo sucedido. Vinculado al Partido Demócrata de Massachussets, se puso en contacto con Robert Drinan, un jesuita miembro del Congreso norteamericano. El 28 y 29 de septiembre fue recibido por el Comité de Relaciones Internacionales de la Cámara de Diputados de Estados Unidos. En la presentación, que compartió con los abogados cordobeses Lucio Garzón Maceda y Gustavo Roca, fue denunciada la violación de los derechos humanos en Argentina. Drinan visitaría Córdoba en noviembre de 1976 como miembro de la delegación de Amnesty Internacional que recibió denuncias in loco. En dicha ciudad, "the most serious harassment occurred" ${ }^{30}$ Mc Carthy, que ya estaba en Washington, se relacionó allí con dos grupos que presionaban contra la Junta: la Washington Office on Latin America (WOLA) que recibía apoyo financiero de un grupo ecuménico y estaba vinculada a la jesuita Universidad de Georgetown; y la Tabor House, dirigida por el carmelita Peter Hinde y la religiosa Betty Cambell.

En Argentina, Nadeau y los familiares hicieron gestiones en el Tercer Cuerpo, la vicaría Castrense, la Casa de Gobierno en Buenos Aires, etc. A fines de septiembre de 1976 permitieron que Nadeau los visitase y les llevara la comunión y la Biblia. Lo recuerdan como "próximo" y "salvador" (e. 2); alguien que se hizo cargo de sus funciones y utilizó los atributos de su cargo para ayudarlos, aún "a riesgo de vida" (e. 1, 4). En efecto, a él se le atribuye la asistencia religiosa y la liberación; ambas conseguidas por su "perseverancia y decisión" (e. 3 ) frente a las circunstancias. Los seminaristas fueron liberados el 9 de octubre. El domingo, 10, participaron en una misa en el barrio Yofre. Durante la ceremonia pasaron autos por la puerta del templo haciendo tiros al aire. A los pocos días abandonaron el país rumbo a Estados Unidos.

El informe del Tercer Cuerpo caratuló a la investigación como "Caso padre [tachado] de la orden de Nuestra Señora de La Salette, y

${ }^{30}$ Amnesty International, Report of an Amnesty International Mission to Argentina, 6-15 November 1976 (London 1977). 
de cinco estudiantes de la misma". La copia consultada en el APM tiene fecha del 4 de noviembre, lleva la firma de Menéndez y está dirigida a Primatesta, quien realizó anotaciones al margen. El documento consigna que en la casa, según denuncias de los vecinos, se "llevaban a cabo reuniones y movimientos sospechosos de personas". Además de la "detención", secuestraron "literatura de contenido subversivo y discos con canciones de protesta de origen boliviano". ${ }^{31}$ Los 22 libros y el disco secuestrado eran "literatura marxista apta para el adoctrinamiento y la prédica de la subversión, y no de carácter teológico o místico, conducente a la formación sacerdotal de seminaristas". ${ }^{32}$ Primatesta señaló los libros del CELAM, con textos de Lucio Gera y Gustavo Gutiérrez, calificados como "autores marxistas"; los títulos de Eduardo Pironio y Helder Cámara, obispos de Mar del Plata y Recife; de Chiara Lubich y Roger Scutz (sic) ${ }^{33}$ referentes de la vida religiosa. El obispo de Córdoba se sorprendió al encontrar esos textos en una lista de material "no teológico". ${ }^{34}$

Según el Tercer Cuerpo, en la "investigación" se probó que Weeks hizo "apología del tercermundismo y parcialización pastoral"; que lideró la ida al barrio con el "pretexto de llevar una vida de pobreza, que aconsejó el no uso del cleriman [sic]" y que no tenía el derecho de admitir al seminario a Pantoja. También, por fuentes confidenciales, se le vincula con los Montoneros; finalmente se hace alusión a su relación con Gustavo Roca y Lucio Garzón Maceda, ${ }^{35}$ a quienes Weeks recién conoció en el hearing en el Congreso norteamericano.

De uno de los seminaristas se dice que lo expulsaron del Seminario Mayor por "revolucionario", que tenía libros "tercermundistas" y que se reconoció "seguidor de los obispos de Medellín", quienes sostenían, según la exégesis del Tercer Cuerpo, el deber de "responder a la violencia con violencia". Primatesta anotó al margen: "No fue por eso (de donde sale esto?) [...] Según testimonio del P. Rector monseñor Disandro, se lo despidió por no querer estudiar latín y someterse a esa disposición del seminario". También subrayó la acusación de que los obispos de Medellín sostenían la violencia.

${ }^{31}$ APM, Menéndez, Informe, p. 1.

${ }^{32}$ Ibidem, p. 5.

${ }^{33}$ Supongo que eran trabajos de Roger Schutz, el "Hermano Roger", fundador de la comunidad religiosa ecuménica de Taizé, en Francia.

${ }^{34}$ APM, Menéndez, Informe, p. 4.

35 Ibidem, p. 8. 
El informe concluye con seis puntos. El primero los acusa de adoctrinamiento marxista, contrastando con la primera acusación policial a Weeks de "trabajar para la CIA", y los cinco restantes critican diferentes aspectos de la opción religiosa de los implicados: la orientación de la congregación, los trabajos apostólicos, la vinculación con el COV y los Cursillos, los libros y la teología tercermundista. Según el documento, los "elementos probatorios son de naturaleza intangible", pero develan el "tercermundismo antropocentrista y ateo, el temporalismo y evangelismo" y la "nueva eclesiología" que apuntaban a la "destrucción de la institución Iglesia". En el último párrafo, Primatesta resalta la calificación de ateo al tercermundismo y la de evangelismo, con signos de interrogación al margen. ${ }^{36}$

\section{LA REDEFINICIÓN DE LO SECULAR}

Los hechos narrados me llevan a reconstruir el argumento de la acción de la siguiente manera. La policía los secuestró por denuncias de un grupo de vecinos filo-fascistas que no quería curas tercermundistas que trataran de "unir a los pobres". La intención era matarlos. Ante el estado público de la situación el Tercer Cuerpo se hace cargo de los presos. Los militares ya vigilaban a la Iglesia de Córdoba: controlaban a las autoridades católicas y tenían grupos de tareas especializados, formados por católicos convencidos de su misión purificadora. La acusación de la autoridad militar es religiosa. El Ejército velaba por la Iglesia, a la que entendían amenazada desde fuera y mal conducida desde dentro.

Los religiosos de La Salette actuaron desde el compromiso asumido con su vocación que, según su interpretación, los llevaba a vivir próximos a los pobres. Esta opción no era sólo de los secuestrados, sino que toda la congregación trabajaba con esa perspectiva. Nadeau avaló la opción saletense ante el Ejército respondiendo a las acusaciones desde el plano religioso: estaban basadas en una mala interpretación de la fe. Según los objetivos planteados al inicio, presentaré ahora el modo en que los diferentes actores sociales católicos redefinieron su rol en la esfera pública, a raíz del terrorismo estatal.

${ }^{36}$ Ibidem, p. 10 


\section{Catolicismos y autoridad Religiosa}

Son varios los católicos que aparecen en el rol de autoridad: los obispos Tortolo, Primatesta y Rubiolo; las autoridades militares y los funcionarios del Gobierno estadounidense. A partir de las formas de autoridad criticadas, Tortolo y Primatesta, intentaré reconstruir la imagen normativa de autoridad que tenían los católicos victimizados.

La crítica fundamental a Primatesta es que él tenía, por ser obispo de Córdoba, una posición privilegiada en el campo social local para defender a las víctimas. Él no era un "pobre tipo". Pero no sólo no usó esos recursos para defender a los seminaristas, sino que incluso justificó el arresto: "[...] no te han llevado gratuitamente, te han llevado porque hiciste algo" (e. 4). Discute, puertas adentro, los informes de Menéndez, pero no desafía al general en su intervención sobre la facultad episcopal de vigilar la ortodoxia y de controlar la fe de los religiosos.

El caso de Tortolo es más grave. Él era el vicario castrense, esto es el jefe de los capellanes militares, y en ese momento la conexión entre Fuerzas Armadas e Iglesia pasaba por los capellanes. Además, hasta abril de ese año, había sido el presidente de la CEA. Tortolo era el gozne entre generales y obispos. Él les negó la comunión y la Biblia. No sólo eso, ante la evidencia de la prueba ("Me paré, bajé mi pantalón, y dije: 'Esto que me hicieron [...] y esto que me hicieron ¿Qué mierda es?" [e. 4]) niega la tortura sufrida. Las víctimas fueron doblemente negadas por el obispo soldado: como hombre del Ejército hubiese podido admitir oficialmente la tortura, pero negó el abuso; como hombre de Iglesia, hubiese podido reconocer que el motivo de la persecución fue el compromiso con la fe, pero los excomulgó de facto. Tortolo negó la identidad católica de las víctimas, precisamente el rasgo identitario que provocó su persecución.

He mostrado que para las víctimas, Dios aparece providente ("las cosas pasan por algo, para evitar el dolor de otros" [e. 2]) y compañero ("la presencia de Dios no faltó ni un instante" [e. 3]). Este es el rasgo que caracteriza su concepción de la divinidad y, por lo tanto, marca su identidad religiosa. Esta idea de Dios "vecino" inspiró una forma de vida religiosa novedosa. La experiencia de un seminario similar a una casa y la de seminaristas "vecinos" muestra que la relación de la Iglesia con el mundo fue entendida como la convivencia con el medio, asumiendo las consecuencias de esta decisión y renunciando a los pri- 
vilegios que la situación histórica concedía a los sacerdotes. Desde el atributo de la "proximidad" de Dios se juzgara la actitud de los líderes religiosos y sociales: los que se acercaron aún sin saber muy bien qué hacer y quienes al contrario, debiendo ser próximos, se alejaron de las víctimas. Nadeau y Rubiolo son los que muestran un liderazgo diferente porque respaldaron a las víctimas en sus opciones religiosas y los defendieron, imitando la vecindad atribuida a Dios.

El estudio del caso nos muestra una transformación en la idea de la autoridad. Unos asumen que la autoridad representa el orden jerárquico del mundo ${ }^{37} \mathrm{y}$, por lo tanto, se relacionan con sus niveles equivalentes de autoridad (las autoridades públicas) y no tanto con los grupos subordinados, aunque estos sean miembros de la Iglesia. La distinción fundamental pasa por la de jerarquía-súbditos, ya que no hay "adentro" o "afuera" de la Iglesia. Otros entienden a la autoridad más horizontal o equitativamente. Por eso conciben su misión como la de acompañar procesos "adentro" de la Iglesia: garantizar el funcionamiento institucional, respaldar las decisiones tomadas con responsabilidad, acompañar a las bases. Ellos son los que asumen la privatización religiosa, en el sentido que le da Casanova: ${ }^{38}$ una religión es privada en tanto que respeta la libertad de conciencia de los sujetos de elegir con autonomía de la autoridad religiosa.

\section{CATOLICISMOS Y SECULARIZACIÓN}

Obregón y Mignone explican la variedad en el comportamiento de la Iglesia católica argentina en función de las líneas teológicas de los obispos. ${ }^{39}$ Señalan tres grandes grupos: los conservadores (mayoritarios), los tradicionalistas (ultramontanos) y los progresistas o renovadores (Obregón distingue en ellos "moderados" y "progresistas"). Si bien la posición teológica es importante, no es el único factor que provocó el posicionamiento de todo el ámbito católico.

Hemos visto que el conflicto que provocó la salida del Seminario Mayor y la creación del Cefyt estuvo relacionado con la respuesta que los actores católicos intentaron dar a la forma de vivir su religión en un

\footnotetext{
${ }^{37}$ Charles Taylor, A Secular Age (Cambridge, MA 2007), pp. 162-166.

${ }^{38}$ Casanova, Public Religion (nota 6), p.40.

${ }^{39}$ Obregón, Entre la cruz y la espada (nota 4); Mignone, Iglesia (nota 2).
} 
ámbito secularizado. El proceso de secularización provocó la recomposición de las creencias, la pluralización de las mismas, el surgimiento de una religión individualizada y las dislocaciones entre lo político y lo religioso. Estos dos actores del proceso de secularización, la religión y la política, tienen una relación porosa, de interpenetración.

Vimos que para algunos actores la secularización se debía a que el mundo se olvidó de Dios, lo que provocó una crisis de valores que era aprovechada por agentes que querían imponer el comunismo en el país. La secularización era algo a combatir. En cambio, para otros católicos, el problema de la falta de fe en la sociedad contemporánea se debía a que el cristianismo se olvidó de las personas concretas, y por eso había que llevarlo allí donde la gente vivía cotidianamente: el trabajo, el barrio, etc. La secularización era un nuevo fenómeno a comprender. Las respuestas religiosas se estructuraron en dos vertientes: recatolizar desde el Estado o desde la vida cotidiana.

El terrorismo de estado, en el contexto del proceso de modernidad, provocó reagrupamientos católicos en la forma de concebir la relación entre la Iglesia y el Estado, entre la religión y la esfera pública. Mientras que unos consideraron que la separación de Iglesia y Estado era un hecho intolerable, para otros era algo no deseado, pero que había que aceptar, y para un tercer grupo era un desafío positivo. Si bien los diferentes sectores católicos no coinciden en las causas de la secularización ni en el programa de acción a emprender, sí acuerdan en una parte del diagnóstico: al mundo le falta Dios. Por eso, los catolicismos pueden ocasionalmente solaparse y acordar en algunas afirmaciones y prácticas religiosas.

Frente al Estado, el catolicismo ocuparía, según los respectivos grupos, un rol como religión nacional, oficial o popular. Tenemos entonces que el catolicismo nacional considera al mundo contemporáneo corrompido y por eso quiere una vuelta a un pasado mitificado, en donde todos los argentinos eran católicos y en la Iglesia no había discordias, se enseñaba latín, se vestía sotana y el Gobierno se ocupaba de lo temporal. No importa la devoción personal, sino la estructura institucional. Es la idea de una "Iglesia" en el sentido de una religión monopólica sobre un territorio, coextensiva a la comunidad política. ${ }^{40}$

${ }^{40}$ Casanova, Public Religion (nota 6), p. 62. 
Hay un catolicismo oficial, que considera a la Iglesia un actor privilegiado de la vida social, diferente al Estado, pero en igualdad de condiciones. Se distingue del Estado, pero se asume como la única instancia de la sociedad civil, a la que sigue identificando como "nación católica". Este catolicismo oficial entiende que la Iglesia debe usar del Estado para garantizar la catolización de la sociedad, pero sin confundirse con él. La modernidad hace surgir a la sociedad civil como una esfera que se ubica entre lo público y lo privado, interactuando con ambas. La Iglesia, que solía ocupar monopólicamente ese espacio, no lo quiere resignar. Por eso no reconocen la existencia de "pares" en la sociedad civil, de otros colectivos que, autónomos de lo eclesial, comparten ese espacio. La negativa de este catolicismo a recibir formalmente a los grupos de derechos humanos ejemplifica esta dificultad de asumir la modernidad. Algunos de los católicos pertenecientes a estos sectores harían gestiones personales por desaparecidos, pero no le otorgarían a las organizaciones de la sociedad civil (Familiares, Madres, Abuelas, etc.) entidad de colectivo social.

Finalmente, hay un catolicismo popular, que entiende que la secularización es causada por el abandono religioso del pueblo. Por lo tanto, evangelizar es anunciar el catolicismo en las bases. En esa dinámica, los católicos encuentran que las masas populares sufren injusticias, que esas injusticias golpean la conciencia cristiana y que hay otros actores sociales entre los pobres. Este catolicismo abandonó la pretensión monopólica y se asumió, rudimentariamente y de un modo incipiente, como un actor entre muchos otros. Reconoce la existencia de una sociedad civil, aunque no lo formule en esos términos. La pluralización se dio también hacia dentro, valorando positivamente las diferentes formas de vivir la consagración religiosa, la variedad de opciones políticas católicas y las múltiples formas de relacionarse con el mundo. Este catolicismo no renuncia a que la religión ocupe un lugar en la esfera pública, pero su intervención en la vida social es desde el compromiso de los sujetos, desde la personalización de las creencias. Se entiende como una fuente que inspira la conciencia de las personas y el compromiso vital para actuar en la esfera pública. Otros reclamos de este grupo tienen que ver con reivindicaciones modernas: los derechos sociales y económicos. El deseo de justicia y la "opción por los pobres" fueron relecturas cristianas de estos derechos modernos. 


\section{CATOlicismos Y MODERNIDADES}

Ahora bien, he dicho que en estos años se produjo en Argetnina una cristalización de tensiones al interior del campo católico frente a la matanza masiva de ciudadanos por parte del Estado. La posición que cada uno de los grupos católicos tuvo frente a la valoración de la vida de los individuos ayudará a entender mejor los comportamientos de los católicos argentinos.

Un logro fundamental de la modernidad nor-atlántica ha sido la defensa de la autonomía de los sujetos más allá de sus creencias. Asumo que proteger el mundo de la vida de la penetración estatal, y la defensa de toda vida humana más allá de las convicciones de la persona son rasgos de modernidad. Creo que la valoración de la vida concreta de los sujetos históricos fue un punto clave en la redefinición de las relaciones entre los católicos y el poder.

Una de las notas del terrorismo estatal argentino fue que subordinó la vida de las personas a los intereses de un Estado que se consideró en guerra. La guerra era contra quienes pensaban distinto en un grado tal que sólo merecían la tortura y la muerte. ${ }^{41}$ Brardinelli afirma que el obispo Novak tuvo una actitud progresista porque rompió el vínculo entre "violencia" y "religión". ${ }^{42}$ Pero creo que en general no hubo una postura de cristianismo pacifista que ayude a explicaciones más generales. ${ }^{43}$ Lo que dividió al ámbito católico fue que frente al hecho concreto de la vida en riesgo unos privilegiaron las organizaciones (tanto a la derecha e izquierda del espectro político) y otros a las personas (más allá de su ideología). Frente al hecho concreto de la tortura y el asesinato masivo, los católicos reaccionaron de modos diversos, en función de los interlocutores que privilegiaban: la organización o el individuo. Así, tendríamos dos principios básicos que guiaron la acción: los que actuaron cuidando su relación con el Estado, y quienes actuaron privilegiando la defensa de la vida de los sujetos. Si a estos

${ }^{41}$ Graciano, Divine Violence (nota 2).

42 Rodolfo Brardinelli, "Resurgimiento religioso, el caso de Mons. Novak y la iglesia de Quilmes durante la dictadura militar (1976-1983)": Scripta Ethnológica XX (1998), pp. 73-84.

${ }^{43}$ Ronald Pagnucco/John Mc Carthy, "Advocating Nonviolent Direct Action in Latin America: The Antecedents and Emergence of Serpaj": Bronislaw Misztal/Anson Shupe (eds.), Religion and Politics in Comparative Perspective (Westport 1992), pp. 125-147. 
dos principios de acción pública (defensa de la vida, defensa del vínculo con el Estado) los cruzamos con los tres modos de reaccionar frente al proceso de secularización (catolicismo nacional, oficial o popular), tendremos como resultado cuatro modos católicos de relacionarse con la modernidad.

Podemos identificar un catolicismo que se asocia al Estado, fundiéndose con él para luchar contra la secularización; contra quienes representan la aceptación de la modernidad, en cualquier grado y variante. Sus seguidores entienden que sólo un Estado católico garantiza una sociedad católica, por eso la fusión. La razón de estado y los intereses eclesiales son lo mismo, no hay distinción. Como la fe regula la vida secular, la diferencia entre pecado y delito no es clara. Las autoridades públicas son las que juzgan en cuestiones terrenas, por lo tanto lo que ellas decidan debe ser apoyado por la Iglesia. Tortolo, el grupo de tareas y Menéndez representan esta postura.

Vemos otro catolicismo que se diferencia del Estado, con cierto grado de autonomía, y que privilegia su rol institucional frente a la sociedad; asume las responsabilidades que implica ese lugar y considera que la institución es más importante que los individuos. Para este grupo, sólo una relación privilegiada con el Estado garantiza la autonomía necesaria para que la Iglesia pueda hacer su tarea. Las acciones eclesiásticas en lo público están supeditadas a mantener una aceptable relación institucional. Consideran a la Iglesia un nexo entre el poder político y la sociedad, por lo que buscan preservarla como un espacio "neutral", fuera de las disputas políticas. Primatesta es quien encarna esta versión católica.

Un tercer catolicismo opta por usar su posición privilegiada, aún arriesgándola, para defender la vida. Operan sobre el Estado usando vínculos premodernos (la posición privilegiada del clero ante las autoridades), pero defienden la vida de los individuos, un valor moderno. Entienden que la vida de una persona no puede ser instrumentalizada y que el catolicismo debe aprovechar sus posiciones en la esfera pública para protegerla. Zueco y Rubiolo representan esta posición.

Finalmente, hay un catolicismo que cree que la religión inspira la conciencia de los sujetos y sus opciones de vida, por lo que el Estado y la sociedad deben respetarla. Si la vida es amenazada por el Estado, el catolicismo como parte de la sociedad debe actuar para garantizarla. Los saletenses, Juanita y Drinan componen este sector. Entienden que sólo un catolicismo que renuncie a sus privilegios históricos y 
asuma la defensa de la vida concreta puede ser una respuesta a la secularización cultural: "nuestro dios es Dios de la vida y no de la muerte" (e. 1). Si desde las teorías clásicas de la secularización esta religiosidad puede ser interpretada como pre-moderno, ya que postula su derecho a intervenir en lo público, en el contexto de modernidad latinoamericana, al postular la defensa de la vida y criticar las injusticias sociales, se transforma en una crítica moderna a prácticas del Estado. 